\title{
Update on Transcatheter Aortic Valve Replacement
}

\author{
Morgan H. Randall · Anthony A. Bavry
}

Received: January 31, 2020 / Published online: February 28, 2020

(C) The Author(s) 2020

\section{ABSTRACT}

Transcatheter aortic valve replacement (TAVR) is a minimally invasive approach to treat symptomatic severe aortic stenosis. The patient populations that have been shown to benefit from this procedure continue to grow with time. Techniques and technology in TAVR persistently advance with a continued trend toward improved outcomes for patients. In this review, we highlight the advances in vascular access, TAVR valve design, progress in reducing procedural complications, and emerging evidence in the field.

Keywords: Alternative transcatheter aortic valve access; Transcatheter aortic valve replacement (TAVR); Transcatheter aortic valve replacement complications; Transcatheter aortic valve review

Enhanced Digital Features To view enhanced digital features for this article go to https://doi.org/10.6084/ m9.figshare.11841660.

M. H. Randall · A. A. Bavry ( $₫)$

Division of Cardiovascular Medicine, University of Florida, Gainesville, FL, USA

e-mail: anthony.bavry@va.gov

\section{A. A. Bavry}

North Florida/South Georgia, Veterans Health

System, Gainesville, FL, USA

\section{Key Summary Points}

Transcatheter aortic valve replacement is a valuable treatment for symptomatic severe aortic stenosis.

Vascular access for transcatheter aortic valve replacement is most often achieved through a transfemoral approach but may also be performed via direct aortic, transaxillary, or transcarotid routes.

There are multiple transcatheter aortic valves approved for use in the United States which have differing design features, strengths, and weaknesses.

While complication rates from transcatheter aortic valve implantation are generally decreasing, adverse outcomes including paravalvular regurgitation and conduction system disturbances leading to pacemaker placement do occur.

Emerging evidence suggests that transcatheter aortic valve replacement may be a viable alternative for patients with bicuspid aortic valves or previously implanted bioprosthetic valves. 


\section{INTRODUCTION}

Aortic stenosis generally develops slowly but, once symptomatic, is associated with a high mortality rate when left untreated [1, 2]. Therefore, aortic valve replacement is an effective way of alleviating stenosis and prolonging life [3]. Replacement has been performed surgically since the 1960s, but in 2002 transcatheter aortic valve replacement (TAVR) emerged as an alternative approach [4]. There have been significant advances in this technique along with expansion of the population in which TAVR can be recommended. This article is based on previously conducted studies and does not contain any studies with human participants or animals performed by any of the authors.

\section{ASSESSMENT OF AORTIC STENOSIS}

Assessing the presence and severity of aortic stenosis is typically initially performed via transthoracic echocardiogram with two-dimensional imaging and Doppler interrogation. However, other imaging modalities such as trans-esophageal echocardiography, computed tomography, or magnetic resonance imaging may be utilized to aid this diagnostic process. Invasive testing is usually reserved to reconcile differences between noninvasive testing and clinical presentation. Conclusions about aortic stenosis severity should be based on multiple data points as opposed to a single test performed in isolation. Echocardiographic findings that point to severe aortic stenosis include a maximum aortic velocity $>4 \mathrm{~m} / \mathrm{s}$, mean pressure gradient $>40 \mathrm{mmHg}$, aortic valve area $<1.0 \mathrm{~cm}^{2}$, and aortic valve area indexed to body surface area $\leq 0.6 \mathrm{~cm}^{2} / \mathrm{m}^{2}$ in patients with normal left ventricular ejection fraction. Among patients with reduced ejection fraction, dobutamine stress echocardiography that reveals an aortic valve area $\leq 1.0 \mathrm{~cm}^{2}$ with maximum aortic velocity $\geq 4 \mathrm{~m} / \mathrm{s}$ is consistent with severe aortic stenosis [2].

The presence of severe aortic stenosis along with symptoms is an indication for replacement [2]. Typical symptoms include dyspnea on exertion, angina, presyncope, syncope, or heart failure symptoms [2]. However, there are data to suggest that intervention prior to symptoms in severe aortic stenosis may be beneficial [5].

\section{PATIENT SELECTION}

As TAVR has been used as an alternative to surgical aortic valve replacement (SAVR), the majority of data compare groups receiving one of these two therapies. The 'PARTNER trial first demonstrated that TAVR was a beneficial therapy in symptomatic aortic stenosis patients who had a prohibitively high surgical risk [1]. Subsequent trials have demonstrated that TAVR has similar outcomes to SAVR in patients with high, intermediate, and low risk from surgery [6-10] (Table 1).

Although TAVR was initially developed as an alternative to SAVR, contraindications do exist. Specifically, this would include patients with comorbidities such that they would be unable to derive benefit from correction of their aortic stenosis [2, 11]. Such patients are typically considered to be "frail". However, defining this term is somewhat controversial with multiple proposed assessment tools in existence [12-15]. Regardless of the tool used to make this assessment, frailty is associated with worse outcomes after TAVR [14].

\section{PROGRAM IMPLEMENTATION}

Success in TAVR outcomes is multifactorial, but experience of the operator and institution appear to be of consequence. Data have demonstrated that there is a learning curve associated with TAVR implantation [12]. Evidence suggests that proficiency is achieved after performing about 50-100 procedures, depending on the method of vascular access $[15,16]$. Institutionally, a case volume of $>50$ per year is suggested to achieve optimal outcomes [12]. However, data suggest that centers with higher procedural volumes on average experience better outcomes as measured by mortality even when excluding this learning period $[17,18]$. 
Table 1 Major TAVR valve trials

\begin{tabular}{|c|c|c|c|c|}
\hline Trial & Valve implanted & $\begin{array}{l}\text { Patient } \\
\text { population }\end{array}$ & Access & Outcomes \\
\hline $\begin{array}{l}\text { PARTNER } \\
\text { A }\end{array}$ & SAPIEN & $\begin{array}{l}\text { Prohibitive } \\
\text { surgical } \\
\text { risk }\end{array}$ & Transfemoral (100\%) & $\begin{array}{l}\text { TAVR superior to medical } \\
\text { therapy } \pm \text { balloon valvuloplasty for } \\
\text { death, inferior for stroke or vascular } \\
\text { complications at } 12 \text { months }\end{array}$ \\
\hline $\begin{array}{l}\text { PARTNER } \\
\text { B }\end{array}$ & SAPIEN & $\begin{array}{l}\text { High surgical } \\
\text { risk }\end{array}$ & $\begin{array}{r}\text { Transfemoral }(70.1 \%) \\
\text { Transapical }(29.9 \%)\end{array}$ & $\begin{array}{l}\text { TAVR equivalent to SAVR for death at } \\
12 \text { months }\end{array}$ \\
\hline $\begin{array}{l}\text { PARTNER } \\
2\end{array}$ & SAPIEN XT & $\begin{array}{l}\text { Intermediate } \\
\text { surgical } \\
\text { risk }\end{array}$ & $\begin{array}{c}\text { Transfemoral }(76.7 \%), \\
\text { Transapical }(17.2 \%), \\
\text { Transaortic }(6.1 \%)\end{array}$ & $\begin{array}{l}\text { TAVR equivalent to SAVR for death or } \\
\text { disabling stroke at } 24 \text { months }\end{array}$ \\
\hline SURTAVI & $\begin{array}{r}\text { CoreValve (84\%); } \\
\text { Evolut R (16\%) }\end{array}$ & $\begin{array}{l}\text { Intermediate } \\
\text { surgical } \\
\text { risk }\end{array}$ & $\begin{array}{l}\text { Transfemoral }(93.6 \%) \\
\text { Transaortic }(4.1 \%), \\
\text { Transsubclavian } \\
(2.3 \%)\end{array}$ & TAVR equivalent to SAVR for \\
\hline $\begin{array}{l}\text { PARTNER } \\
3\end{array}$ & SAPIEN 3 & $\begin{array}{l}\text { Low surgical } \\
\text { risk }\end{array}$ & Transfemoral (100\%) & $\begin{array}{l}\text { TAVR superior to SAVR for death, stroke, } \\
\text { or hospitalization at } 12 \text { months }\end{array}$ \\
\hline $\begin{array}{l}\text { Evolut low } \\
\text { risk }\end{array}$ & $\begin{array}{l}\text { CoreValve (3.6\%); } \\
\text { Evolut R (74.1\%); } \\
\text { Evolut Pro } \\
(22.3 \%)\end{array}$ & $\begin{array}{l}\text { Low surgical } \\
\text { risk }\end{array}$ & $\begin{array}{l}\text { Transfemoral }(99 \%) \\
\text { Transaortic }(0.4 \%), \\
\text { Transsubclavian } \\
(0.6 \%)\end{array}$ & $\begin{array}{l}\text { TAVR equivalent to SAVR for death or } \\
\text { disabling stroke at } 24 \text { months }\end{array}$ \\
\hline
\end{tabular}

The Centers for Medicare \& Medicaid Services has set standards that must be met for coverage of TAVR procedures. These were published in 2013 [19] and include requirements such as a multidisciplinary team with cardiac surgeons, interventional cardiologists, imaging specialists, heart failure specialists, cardiac anesthesiologists, intensivists, nurses, and social workers. Case volume requirements exist for the individual providers as well as for institutions offering TAVR. For example, an interventional cardiologist must have experience with at least 100 structural heart procedures in their career or 30 left-sided structural procedures. This document also specifically excludes coverage for patients who would not be expected to derive benefit from the procedure due to co-morbidities [19].

\section{PROCEDURAL METHODS}

There have been multiple vascular access techniques for TAVR implantation [20, 21]. There have been no randomized trials comparing different approaches, yet the transfemoral approach has been widely favored based on the available evidence $[20,21]$. In practice, the chosen approach is determined by the individual patient's anatomy and comorbidities $[20,21]$.

The transfemoral approach is currently chosen for the majority of TAVR cases [21]. This approach has the most robust data available, which suggests it is superior to alternate approaches [21], and because of its wide use, it is the standard by which other approaches are compared.

The transapical approach for TAVR was historically used in half of the cases; however, most programs no longer employ this access site. This 
approach is the only antegrade approach to implantation but requires general anesthesia and surgical cutdown. The transapical approach has also been associated with lower ejection fraction post-procedure, increased rate of blood transfusions, increased risk of bleeding, longer hospital stay, and increased mortality compared with the transfemoral approach [21]. Conversely, data suggest that there are similar rates of stroke, pacemaker implantation, and mortality compared with SAVR [20]. In the setting of increased reported rates of complications and greater use of hospital resources, the transapical approach is becoming less common in practice and now accounts for $<5 \%$ of all cases performed $[20,21]$.

Direct aortic access requires either partial sternotomy or mini-thoracotomy to achieve direct visualization of the aorta. Due to the close proximity of the access site to the aortic valve, this approach has the ability to avoid occlusions that may exist at other potential sites. While there is evidence that short- and long-term mortality rates with the direct aortic approach are lower compared to the transapical approach, results are inferior to transfemoral [20]. Furthermore, evidence suggests that there are higher rates of major bleeding and arrhythmias compared with the transfemoral approach [20].

The transaxillary approach has been used because of its proximity to the aortic valve, which allows for improved control of the device. In the majority of cases, the left axillary artery is used, as opposed to the right, because of the more coaxial approach. Outcomes with the transaxillary are similar to those with the transfemoral approach [21].

Transcarotid access uses a similar direct approach to transaxillary and therefore is primarily performed using the left carotid artery. To ensure adequate perfusion to the brain, preprocedural imaging is critical to ensure adequate collateral circulation [21]. Data suggest that outcomes are similar to those of transfemoral access in terms of stroke, bleeding, and mortality $[20,21]$. Advantages to the transcarotid approach include the ability to promote early ambulation, decreased requirement for anesthesia, and shorter length of stay $[20,21]$.

\section{AVAILABLE TRANSCATHETER AORTIC VALVES}

As indications and techniques for TAVR implantation have evolved, so has valve design. Device design has progressed with newer generations of valves improving outcomes compared with their predecessors. In the United States, approved TAVR valves are the SAPIEN 3 and SAPIEN 3 Ultra manufactured by Edwards Lifesciences, Evolut Pro+ manufactured by Medtronic, and Lotus Valve System manufactured by Boston Scientific.

The SAPIEN 3 valve was tested in the PARTNER 3 trial and demonstrated superiority to surgical aortic valve replacement in low-risk patients. This device has been approved by the United States Food and Drug Administration since June 2017. Arterial access through a 5.5$\mathrm{cm}$ diameter or larger artery is required for a $14 \mathrm{~F}$ sheath to deliver the device. The valve itself is manufactured in 20, 23, 26, and 29-mm diameters, which allow for differences in individual anatomy [22]. The SAPIEN 3 valve is a balloonexpandable device and has proven to have superior outcomes with regard to all-cause mortality, stroke, rehospitalization within 1 year, new-onset atrial fibrillation, and major bleeding compared with SAVR in these low-risk patients [7]. Outcomes were equivalent with regard to major vascular complications, pacemaker implantation, and residual aortic valve gradient. However, higher rates of new left bundle branch block and paravalvular regurgitation occurred in the TAVR cohort [7].

Edwards Lifesciences also gained approval for the SAPIEN 3 Ultra valve in August of 2019. This system is also a balloon-expandable device and is manufactured in 20,23 , and $26-\mathrm{mm}$ diameters. It is also delivered by a $14 \mathrm{~F}$ sheath, but requires a $6 \mathrm{~mm}$ or larger vessel for vascular access. While the SAPIEN 3 Ultra has not yet featured in a published randomized control trial, available data suggest that, along with the SAPIEN 3, it achieves superior outcomes to those of the original SAPIEN valve [22]. 
The Evolut Pro+ is the most recent TAVR product offered by Medtronic. It is a self-expanding supra-annular bioprosthesis available in $23,26,29$, and 34-mm diameters. It can be deployed through a $5.5-\mathrm{mm}$ or larger vessel using a $14 \mathrm{~F}$ or $18 \mathrm{~F}$ delivery system [23]. The featured design improvement over its predecessor, the Evolut Pro, is an external porcine pericardial wrap over the lower cells of the valve intended to decrease perivalvular regurgitation [24]. Indeed, available data have shown a $16 \%$ relative increase in patients with no or minimal paravalvular regurgitation with the Evolut Pro+ compared with the Evolut Pro [24]. This new generation also shows decreased rates of pacemaker implantation compared with available alternatives [24].

Another option for TAVR valves in the United States is the Lotus Valve System manufactured by Boston Scientific. This product employs controlled mechanical expansion to deploy. This mechanism allows for evaluation of hemodynamics and, if necessary, repositioning prior to release [25]. It uses an $18 \mathrm{~F}$ or $20 \mathrm{~F}$ delivery system to implant a 23,25 , or $27-\mathrm{mm}$ valve $[26,27]$. The minimum artery size needed for implantation varies by access site and introducer set. For example, with a transfemoral approach, a $5.9-\mathrm{mm}$ or larger artery diameter is necessary for the iSLEEVE introducer set while the Lotus introducer set requires a $6.5-\mathrm{mm}$ or larger vessel diameter [26]. Boston Scientific has highlighted the repositioning function as well as external polymer wrap as features that have particular value [28].

Comparisons between the SAPIEN 3, SAPIEN 3 Ultra, Evolut Pro+, and Lotus prove difficult because of limited available data. Comparisons between balloon-expanding and self-expanding valves primarily include patients with previous generations of valves. These data have demonstrated that self-expanding valves are superior to balloon-expandable valves in terms of pacemaker rates and PVR for small annuli [29]. However, mortality outcomes have been equivocal, and these data are likely obsolete with newer designs aimed at reducing such complications [3, 29, 30] (Fig. 1 [23, 28, 31]). The most relevant direct comparison has revealed that the SAPIEN 3 and Lotus valves have similar mortality rates, which is consistent with previous studies [32]. This study was further consistent with previous data by revealing a lower rate of pacemaker implantation for the SAPIEN 3 balloon-expanding valve compared with the Lotus mechanical expansion valve [32].

\section{DEVICE COMPLICATIONS}

While TAVR does offer advantages over SAVR, some well-described adverse outcomes have been reported. The most pertinent procedural complications include paravalvular regurgitation and conduction disturbances including left bundle branch block or high-degree atrioventricular block requiring pacemaker [17, 33, 34]. These metrics in particular have improved over time but remain inferior to those of SAVR.

Paravalvular regurgitation after TAVR has been a measure of quality since inception, as moderate-to-severe paravalvular regurgitation has proven to be a predictor of mortality [35]. Newer-generation valves have placed an emphasis on minimizing this complication, as evidenced by the addition of an external wrap on the Evolut Pro+ and increased height of the outer skirt for the SAPIEN 3 Ultra [22, 23]. Original data from PARTNER 3 revealed a moderate-to-severe paravalvular regurgitation rate with the SAPIEN 3 of $0.8 \%$ [7]. The limited data available for the SAPIEN 3 Ultra show a moderate paravalvular regurgitation rate of $1.4 \%$, with no cases of severe paravalvular regurgitation [36]. No outcome data are available at this time for the Evolut Pro+, but paravalvular regurgitation rates for its predecessor, the Evolut Pro, have been reported as low as 5\% [30]. One-year follow-up data from the Lotus system showed no severe perivalvular regurgitation and only $0.4 \%$ of patients exhibiting moderate perivalvular regurgitation [37]. This is in contrast to the approximately $10 \%$ rate of moderate or severe paravalvular regurgitation in early devices [1].

Conduction disturbances after TAVR have potential morbidity and mortality. This complication is likely the result of the close proximity between the conduction system and the 


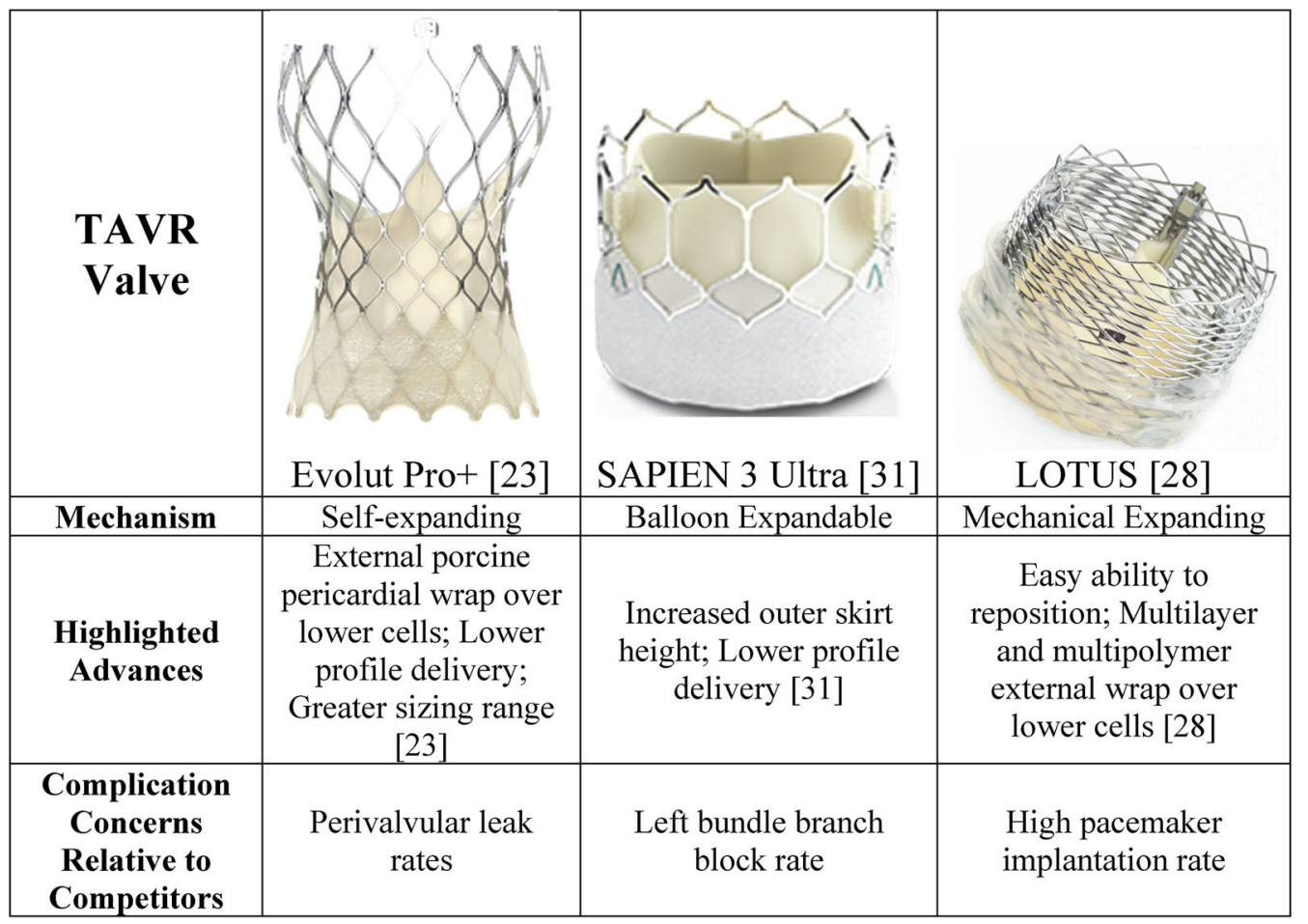

Fig. 1 Comparison of recent TAVR valves

aortic annulus [17, 33, 34]. However, data quantifying the rate of this complication are likely obsolete, as they include previous generations of devices. For example, left bundle branch block rates vary in reported literature from 4 to $65 \%$ depending on the particular valve utilized [33]. The presence of a left bundle branch block is of consequence as this finding, especially with a QRS duration $>150 \mathrm{~ms}$, is associated with higher mortality [33]. More data from the PARTNER 3 trial using the SAPIEN 3 system were published in May 2019 and revealed a $23.7 \%$ rate of left bundle branch block at 1 year [7]. Early data from the Evolut Pro have shown reduced incidence of left bundle branch block compared with the Evolut $\mathrm{R}$ device, but it remains relatively high at $38.8 \%$ [30]. This information helps define a range for which to expect left bundle branch block to develop, but these outcomes may not accurately reflect rates of the Evolut Pro+ or SAPIENT 3 Ultra. The Lotus valve has a relatively high rate of pacemaker implantation as discussed below but data on the rate of left bundle branch block after valve implantation are scarce.
High-degree atrioventricular block requiring pacemaker placement is another adverse event of TAVR that occurs at a rate significantly higher than SAVR. Reported rates of this complication have a wide distribution, which is likely due to the heterogeneity of the procedure [33]. Self-expanding valves have been shown to carry a higher risk than balloon-expanding devices $[17,33,34]$. The majority of high-degree atrioventricular block occurs within $24 \mathrm{~h}$ of implantation, but this complication can develop $>48 \mathrm{~h}$ afterwards [33]. While there is variation in pacemaker rates after TAVR, which is likely related once again to the heterogeneity of the procedure, data suggest an overall occurrence of approximately 13\% [33]. Interestingly, newer-generation valves have not reliably resulted in lower pacemaker rates as the SAPIEN 3 valve has a higher rate of pacemaker implantation than previous SAPIEN valves [33]. In fact, the Lotus valve has reported a pacemaker implantation rate of $34.6-41.7 \%$ in patients who did not previously have a pacemaker at baseline $[25,27]$. 


\section{EMERGING EVIDENCE}

Indications for TAVR have been continually expanding since the inception of this procedure. This gradual inclusion of patient populations has generated data in patients with bicuspid aortic valves and patients with previous aortic valve replacements, suggesting beneficial effects. Concomitantly, the resources that are truly necessary for a successful TAVR program are also being examined.

Major trials to date have excluded patients with bicuspid aortic valve. This is likely due to the more difficult technical aspects of treating this population, as a bicuspid aortic valve is associated with an elliptical or asymmetric annulus and enlarged ascending aorta [38-40]. However, this anomaly is the most prevalent congenital heart disease, involving $1 \%$ of the population, and is the etiology of roughly $20 \%$ of patients over 80 years old with aortic stenosis [38-40]. With this significant population of aortic stenosis patients, TAVR has been provided as an off-label solution to treat this disease, with multiple smaller studies published. Data have indeed revealed higher rates of procedural complications compared with patients with tricuspid valves. Specifically, patients with bicuspid aortic valve have higher rates of conversion to surgical valve replacement, moderate or severe paravalvular regurgitation, and device failure [40]. In contrast, 30-day and 1-year mortality outcomes, rates of stroke, vascular complications, and pacemaker implantation were equivalent to those of patients with tricuspid valves [40]. These outcomes have been consistent regardless of the generation of TAVR valve, with the only exception of higher rates of device failure with first-generation valves [40]. This suggests that newer valves will have similar complication rates, but evidence for the SAPIEN 3 Ultra, Evolut Pro+, and Lotus valve is currently lacking.

Another population of patients who have undergone off-label TAVR outside of large trials are those with degenerative bioprosthetic aortic valves. Valve-in-valve TAVR has been performed as an alternative to redo SAVR particularly in patients at high surgical risk [41, 42]. Pooled data in this population demonstrate a lower 30-day mortality, lower rate of blood transfusions, lower rate of pacemaker placement, and lower 5-year mortality in patients undergoing valve-in-valve TAVR compared with redo SAVR [42]. Adversely, paravalvular regurgitation has been reported as a more common complication in valve-in-valve TAVR compared with SAVR, but this could be partially explained by the use of older-generation valves in procedures included in analysis [41]. The logical conclusion from these results is that valve-in-valve TAVR is a viable and potentially desirable alternative to redo SAVR.

Post-procedural antithrombotic therapy is routinely prescribed, yet little evidence exists to support current recommendations. To avoid the morbidity and mortality associated with stroke, dual antiplatelet therapy is most commonly prescribed for 3-6 months. However, the presence of atrial fibrillation, coronary disease requiring percutaneous intervention, or bleeding risk can influence therapy at the individual patient level. Therefore, a number of clinical trials are underway examining an optimal treatment strategy for patients undergoing TAVR [43].

The level of institutional and multidisciplinary support needed for successful TAVR programs has evolved as techniques and equipment have advanced. Anesthesia for TAVR procedures was initially performed with general anesthesia, but this is becoming increasingly less common in favor of conscious sedation $[1,44]$. In fact, available data fail to show a difference in outcomes between those patients who undergo TAVR with general anesthesia versus those who have conscious sedation, or even whether or not an anesthesiologist is physically present for the procedure [44-46]. TAVR procedures performed with conscious sedation have been shown to result in decreased morbidity at 30 days, shorter intensive care unit stays, and decreased overall length of stay compared with general anesthesia [44]. These outcome benefits, however, have not shown to decrease cost of admission [45]. Instead, these data bring into question whether this service or other resources deemed mandatory for TAVR programs are truly necessary. 


\section{CONCLUSIONS}

TAVR is an evolving procedure with persistent advancement in procedural methods, devices, patient selection, and resource utilization. Outcomes generally have been good and have improved since the inception of this procedure. However, there remains opportunity to decrease complications and improve outcomes, which continues to drive innovation in this space.

\section{ACKNOWLEDGEMENTS}

Funding. No funding or sponsorship was received for this study or publication of this article.

Authorship. All named authors meet the International Committee of Medical Journal Editors (ICMJE) criteria for authorship for this article, take responsibility for the integrity of the work as a whole, and have given their approval for this version to be published.

Disclosures. Anthony Bavry is a member of the journal's Editorial Board. Morgan Randall has nothing to disclose.

Compliance with Ethics Guidelines. This article is based on previously conducted studies and does not contain any studies with human participants or animals performed by any of the authors.

Open Access. This article is licensed under a Creative Commons Attribution-NonCommercial 4.0 International License, which permits any non-commercial use, sharing, adaptation, distribution and reproduction in any medium or format, as long as you give appropriate credit to the original author(s) and the source, provide a link to the Creative Commons licence, and indicate if changes were made. The images or other third party material in this article are included in the article's Creative Commons licence, unless indicated otherwise in a credit line to the material. If material is not included in the article's Creative Commons licence and your intended use is not permitted by statutory regulation or exceeds the permitted use, you will need to obtain permission directly from the copyright holder. To view a copy of this licence, visit http://creativecommons.org/licenses/by$\mathrm{nc} / 4.0 /$.

\section{REFERENCES}

1. Leon MB, Smith CR, Mack M, Miller DC, Moses JW, Svensson LG, et al. Transcatheter aortic-valve implantation for aortic stenosis in patients who cannot undergo surgery. $\mathrm{N}$ Engl $\mathrm{J}$ Med. 2010;363(17):1597-607.

2. Nishimura RA, Otto CM, Bonow RO, Carabello BA, Erwin JP 3rd, Guyton RA, et al. 2014 AHA/ACC Guideline for the Management of Patients With Valvular Heart Disease: executive summary: a report of the American College of Cardiology/ American Heart Association Task Force on Practice Guidelines. Circulation. 2014;129(23):2440-92.

3. Mahtta D, Elgendy IY, Bavry AA. From CoreValve to Evolut PRO: reviewing the journey of self-expanding transcatheter aortic valves. Cardiol Ther. 2017;6(2):183-92.

4. Cribier A, Eltchaninoff $\mathrm{H}$, Bash A, Borenstein $\mathrm{N}$, Tron C, Bauer F, et al. Percutaneous transcatheter implantation of an aortic valve prosthesis for calcific aortic stenosis: first human case description. Circulation. 2002;106(24):3006-8.

5. Kang DH, Park SJ, Lee SA, Lee S, Kim DH, Kim HK, et al. Early surgery or conservative care for asymptomatic aortic stenosis. N Engl J Med. 2020;382(2): 111-9.

6. Leon MB, Smith CR, Mack MJ, Makkar RR, Svensson LG, Kodali SK, et al. Transcatheter or surgical aorticvalve replacement in intermediate-risk patients. N Engl J Med. 2016;374(17):1609-20.

7. Mack MJ, Leon MB, Thourani VH, Makkar R, Kodali SK, Russo $M$, et al. Transcatheter aortic-valve replacement with a balloon-expandable valve in low-risk patients. N Engl J Med. 2019;380(18): 1695-705.

8. Popma JJ, Deeb GM, Yakubov SJ, Mumtaz M, Gada $\mathrm{H}$, O'Hair D, et al. Transcatheter aortic-valve replacement with a self-expanding valve in low-risk patients. N Engl J Med. 2019;380(18):1706-15.

9. Reardon MJ, Van Mieghem NM, Popma JJ, Kleiman NS, Sondergaard L, Mumtaz M, et al. Surgical or 
transcatheter aortic-valve replacement in intermediate-risk patients. N Engl J Med. 2017;376(14): 1321-31.

10. Smith CR, Leon MB, Mack MJ, Miller DC, Moses JW, Svensson LG, et al. Transcatheter versus surgical aortic-valve replacement in high-risk patients. N Engl J Med. 2011;364(23):2187-98.

11. Centers for Medicare and Medicaid Services. National Coverage Determination (NCD) for Glycated Hemoglobin/Glycated Protein (190.21). https://www.cms. gov/medicare-coverage-database/(S(0vbjxs45yksgs35 5egu1de45))/details/ncd-details.aspx?NCDId $=100$ \&CALId = 189 \&CalName = Glycated + Hemoglobin $\% 2$ FGlycated + Protein + (Addition + of + ICD-9$\mathrm{CM}+271.3 \% 2 \mathrm{C}+$ Intestinal + disaccharidase + deficiencies + and + disaccharide + malabsorption) $\& \mathrm{bc}=$ AAAAABAAgAIAAA\%3D\%3D. Accessed $20 \mathrm{Jan}$ 2020.

12. Bavaria JE, Tommaso CL, Brindis RG, Carroll JD, Deeb GM, Feldman TE, et al. 2018 AATS/ACC/SCAI/ STS Expert Consensus Systems of Care Document: Operator and institutional recommendations and requirements for transcatheter aortic valve replacement: a joint report of the American Association for Thoracic Surgery, American College of Cardiology, Society for Cardiovascular Angiography and Interventions, and Society of Thoracic Surgeons. J Am Coll Cardiol. 2019;73(3):340-74.

13. Finn M, Green P. The influence of frailty on outcomes in cardiovascular disease. Rev Esp Cardiol (Engl Ed). 2015;68(8):653-6.

14. Green P, Woglom AE, Genereux P, Daneault B, Paradis JM, Schnell S, et al. The impact of frailty status on survival after transcatheter aortic valve replacement in older adults with severe aortic stenosis: a single-center experience. JACC Cardiovasc Interv. 2012;5(9):974-81.

15. Henn MC, Percival T, Zajarias A, Melby SJ, Lindman $\mathrm{BR}$, Quader N, et al. Learning alternative access approaches for transcatheter aortic valve replacement: implications for new transcatheter aortic valve replacement centers. Ann Thorac Surg. 2017;103(5):1399-405.

16. Carroll JD, Vemulapalli S, Dai D, Matsouaka R, Blackstone E, Edwards F, et al. Procedural experience for transcatheter aortic valve replacement and relation to outcomes: the STS/ACC TVT Registry. J Am Coll Cardiol. 2017;70(1):29-41.

17. Cormican D, Jayaraman A, Villablanca P, Ramakrishna $H$. TAVR procedural volumes and patient outcomes: analysis of recent data. J Cardiothorac Vasc Anesth. 2020;34(2):545-50.
18. Vemulapalli S, Carroll JD, Mack MJ, Li Z, Dai D, Kosinski AS, et al. Procedural volume and outcomes for transcatheter aortic-valve replacement. N Engl J Med. 2019;380(26):2541-50.

19. Centers for Medicare and Medicaid Services. National coverage determination (NCD) for transcatheter aortic valve replacement (TAVR) (20.32). https://www.cms.gov/medicare-coverage-database/ details/ncd-details.aspx?NCDId=355\&ncdver $=1 \& b c$ =AAAAgAAAAAAA\&. Accessed 20 Jan 2020.

20. Overtchouk P, Modine T. Alternate access for TAVI: stay clear of the chest. Interv Cardiol. 2018;13(3): 145-50.

21. Pour-Ghaz I, Raja J, Bayoumi M, Manolukas T, Khouzam RN, Ibebuogu UN. Transcatheter aortic valve replacement with a focus on transcarotid: a review of the current literature. Ann Transl Med. 2019;7(17):420.

22. United States Food and Drug Administration. Edwards SAPIEN 3 Transcatheter Heart Valve System and Edwards SAPIEN 3 Ultra Transcatheter Heart Valve System-P140031/S085. https://www. fda.gov/medical-devices/recently-approved-devices /edwards-sapien-3-transcatheter-heart-valve-systemand-edwards-sapien-3-ultra-transcatheter-heart. Accessed 20 Jan 2020.

23. Medtronic. EVOLUT PRO + SYSTEM. https://www. medtronic.com/us-en/healthcare-professionals/ products/cardiovascular/transcatheter-aortic-heartvalves/evolut-pro-plus.html. Accessed 20 Jan 2020.

24. Forrest JK, Mangi AA, Popma JJ, Khabbaz K, Reardon MJ, Kleiman NS, et al. Early outcomes with the Evolut PRO repositionable self-expanding transcatheter aortic valve with pericardial wrap. JACC Cardiovasc Interv. 2018;11(2):160-8.

25. Falk V, Wohrle J, Hildick-Smith D, Bleiziffer S, Blackman DJ, Abdel-Wahab M, et al. Safety and efficacy of a repositionable and fully retrievable aortic valve used in routine clinical practice: the RESPOND Study. Eur Heart J. 2017;38(45):3359-66.

26. United States Food and Drug Administration. LOTUS Edge ${ }^{\mathrm{TM}}$ Valve System. https://www.fda.gov/ medical-devices/recently-approved-devices/lotus-e dgetm-valve-system-p180029. Accessed 20 Jan 2020 .

27. Reardon MJ, Feldman TE, Meduri CU, Makkar RR, O'Hair D, Linke A, et al. Two-year outcomes after transcatheter aortic valve replacement with mechanical vs self-expanding valves: the REPRISE III randomized clinical trial. JAMA Cardiol. 2019;4(3):223-9. 
28. Boston Scientific. LOTUS Edge ${ }^{\mathrm{TM}}$ aortic valve system. https://www.bostonscientific.com/en-US/ medical-specialties/structural-heart/lotus-edge/tavr -valve-product-overview.html. Accessed 26 Jan 2020.

29. Abdelghani M, Mankerious N, Allali A, Landt M, Kaur J, Sulimov DS, et al. Bioprosthetic valve performance after transcatheter aortic valve replacement with self-expanding versus balloonexpandable valves in large versus small aortic valve annuli: insights from the CHOICE trial and the CHOICE-Extend registry. JACC Cardiovasc Interv. 2018;11(24):2507-18.

30. Rao G, Sheth S, Donnelly J, Scatola A, Tariq U, Laighold S, et al. Early real-world experience with CoreValve Evolut PRO and R Systems for transcatheter aortic valve replacement. J Interv Cardiol. 2019;2019:1906814.

31. Edwards Lifesciences Corporation. Introducing the SAPIEN 3 Ultra System. https://www.edwards.com/ gb/devices/heart-valves/transcatheter-SAPIEN-3Ultra. Accessed 26 Jan 2020.

32. Seeger J, Gonska B, Rottbauer W, Wohrle J. Outcome with the repositionable and retrievable Boston Scientific Lotus Valve compared with the balloon-expandable Edwards Sapien 3 Valve in patients undergoing transfemoral aortic valve replacement. Circ Cardiovasc Interv. 2017;10(6): e004670.

33. Auffret V, Puri R, Urena M, Chamandi C, RodriguezGabella T, Philippon F, et al. Conduction disturbances after transcatheter aortic valve replacement: current status and future perspectives. Circulation. 2017;136(11):1049-69.

34. Nazif TM, Dizon JM, Hahn RT, Xu K, Babaliaros V, Douglas PS, et al. Predictors and clinical outcomes of permanent pacemaker implantation after transcatheter aortic valve replacement: the PARTNER (Placement of AoRtic TraNscathetER Valves) trial and registry. JACC Cardiovasc Interv. 2015;8(1 Pt A):60-9.

35. Takagi H, Umemoto T, Group A. Impact of paravalvular aortic regurgitation after transcatheter aortic valve implantation on survival. Int J Cardiol. 2016;221:46-51.

36. Saia F, Gandolfo C, Palmerini T, Berti S, Doshi SN, Laine M, et al. Sapien 3 Ultra balloon-expandable transcatheter aortic valve: in-hospital and 30-day results from the multicentre S3U registry. EuroIntervention. 2020;15(14):1240-7.

37. Van Mieghem NM, Wohrle J, Hildick-Smith D, Bleiziffer S, Blackman DJ, Abdel-Wahab M, et al. Use of a repositionable and fully retrievable aortic valve in routine clinical practice: the RESPOND study and RESPOND extension cohort. JACC Cardiovasc Interv. 2019;12(1):38-49.

38. Aalaei-Andabili SH, Beaver TM, Petersen JW, Anderson RD, Karimi A, Thoburn E, et al. Early and midterm outcomes of transcatheter aortic valve replacement in patients with bicuspid aortic valves. J Card Surg. 2018;33(9):489-96.

39. Bob-Manuel T, Heckle MR, Ifedili IA, Wang J, Ibebuogu UN. Outcomes of transcatheter aortic valve replacement in bicuspid aortic valve stenosis. Ann Transl Med. 2019;7(5):102.

40. Ueshima D, Nai Fovino L, Brener SJ, Fabris T, Scotti A, Barioli A, et al. Transcatheter aortic valve replacement for bicuspid aortic valve stenosis with first- and new-generation bioprostheses: a systematic review and meta-analysis. Int $\mathrm{J}$ Cardiol. 2020;298:76-82.

41. Takagi H, Mitta S, Ando T. Meta-analysis of valvein-valve transcatheter versus redo surgical aortic valve replacement. Thorac Cardiovasc Surg. 2019;67(4):243-50.

42. Tam DY, Dharma C, Rocha RV, Ouzounian M, Wijeysundera HC, Austin PC, et al. Transcatheter $\mathrm{ViV}$ versus redo surgical AVR for the management of failed biological prosthesis: early and late outcomes in a propensity-matched cohort. JACC Cardiovasc Interv. 2020. https://doi.org/10.1016/j.jcin. 2019.10.030.

43. Saito Y, Nazif T, Baumbach A, Tchetche D, Latib A, Kaple R, et al. Adjunctive antithrombotic therapy for patients with aortic stenosis undergoing transcatheter aortic valve replacement. JAMA Cardiol. 2019;5:92-101.

44. Hyman MC, Vemulapalli S, Szeto WY, Stebbins A, Patel PA, Matsouaka RA, et al. Conscious sedation versus general anesthesia for transcatheter aortic valve replacement: insights from the National Cardiovascular Data Registry Society of Thoracic Surgeons/American College of Cardiology Transcatheter Valve Therapy Registry. Circulation. 2017;136(22):2132-40.

45. Ahmad M, Patel JN, Vipparthy SC, Divecha C, Barzallo PX, Kim M, et al. Conscious sedation versus general anesthesia in transcatheter aortic valve replacement: a cost and outcome analysis. Cureus. 2019;11(6):e4812.

46. Konigstein M, Ben-Shoshan J, Zahler D, Flint N, Margolis G, Granot Y, et al. Outcome of patients undergoing TAVR with and without the attendance of an anesthesiologist. Int J Cardiol. 2017;241: 124-7. 